\title{
A política migratória brasileira em perspectiva comparada: uma análise a partir e sobre o Índice de Concessão de Cidadania
}

\author{
The Brazilian Migration Policy in \\ Comparative Perspective: an analysis from \\ and about the Citizenship Index
}

DOI: $10.21530 /$ ci.v11n2.2016.481

\author{
Eduardo Matos Oliveira ${ }^{1}$ \\ Marcelo de Almeida Medeiros ${ }^{2}$ \\ Leonardo Gill Correia Santos ${ }^{3}$ \\ Mariana Cockles Teixeira ${ }^{4}$
}

\section{Resumo}

O objetivo deste trabalho é fazer uma extensão do estudo apresentado por J. Fitzgerald, D. Leblang e J. Teets no artigo "Defying the Law of Gravity: The Political Economy of International Migration” na revista World Politics em 2014. Os autores analisam a relação entre o fluxo migratório internacional e as condições políticas internas nos países de destino. Para isso, eles elaboraram um índice que avalia o rigor no procedimento de concessão de cidadania em centros receptores e utilizaram essa medida como referência para a abertura política do país em relação aos imigrantes. Entretanto, o Brasil não foi acrescentado na lista de países que foram codificados no índice como ponto de destino. Iremos, portanto, suprir tal lacuna, a fim de comparar a política brasileira de concessão de nacionalidade para estrangeiros com outros países que também recebem um grande fluxo de pessoas. A partir dos resultados foi possível questionar a validade da medida, visto que o Brasil apresenta um perfil de abertura política de acordo com os critérios elencados pelo índice, apesar da legislação brasileira ter um caráter autoritário e conter sérias restrições à liberdade dos imigrantes.

Palavras-Chave: política migratória; concessão de cidadania; nacionalidade; Índice de Concessão de Cidadania.

1 Mestrando em Ciência Política na Universidade Federal de Pernambuco e Advogado.

2 Professor Associado de Ciência Política da Universidade Federal de Pernambuco (UFPE), Pesquisador PQ - 1C do Conselho Nacional de Desenvolvimento Científico e Tecnológico (CNPq).

3 Mestrando em Ciência Política na Universidade Federal de Pernambuco.

4 Mestranda em Ciência Política na Universidade Federal de Pernambuco.

Artigo recebido em 20/05/2016 e aprovado em 19/08/2016. 


\begin{abstract}
The main purpose of this article is to extend the research developed by J. Fitzgerald, D. Leblang e J. Teets published on the $66^{\text {th }}$ volume of "World Politics" in 2014. The authors analyzed the relation between international migration flow and political conditions in receiving countries. In order to evaluate the migration policy, they developed an index that measures citizenship granting procedures inside those countries, which they use as reference for national political openness toward immigrants. As Brazil was not included on the list of the countries defined as destination points, the paper aims to fill this gap, by comparing Brazilian citizenship granting policy with other countries that also receive large flows of immigrants. As a result of the study, it was possible to question the validity of measures proposed by the index. According to them, Brazil would be characterized as a highly accessible country, contrasting with a reality of authoritarian immigration laws that include various restrictions to the liberty of immigrants.
\end{abstract}

Keywords: Migration policy; citizenship granting; nationality; citizenship index.

\title{
Introdução
}

O objetivo deste trabalho é fazer uma extensão do estudo apresentado por J. Fitzgerald, D. Leblang e J. Teets no artigo "Defying the Law of Gravity: The Political Economy of International Migration” na revista World Politics, em 2014. Os autores analisam a relação entre o fluxo migratório internacional e as condições políticas internas nos países de destino. Para isso, eles elaboraram um índice ${ }^{5}$ que avalia o rigor no procedimento de concessão de cidadania em centros receptores e utilizaram tal medida como referência para a abertura política do país em relação aos imigrantes.

Entretanto, o Brasil não foi acrescentado na lista de países que foram codificados no índice como ponto de destino. Iremos, portanto, suprir essa lacuna, a fim de comparar a política brasileira de concessão de nacionalidade para estrangeiros com outros países que também recebem um grande fluxo de pessoas. Com esse objetivo, nós faremos a codificação do Brasil de acordo com os critérios escolhidos pelos autores na composição do indicador.

5 Fizemos uma tradução livre do termo inglês “citizenship index". Optamos por traduzir para “Índice de Concessão de Cidadania” com o objetivo de tornar mais claro que se trata de questões relacionadas à nacionalidade. 
No primeiro tópico deste trabalho, iremos fazer uma revisão de bibliografia sobre as teorias das migrações internacionais, a fim de posteriormente explicar a importância da inserção da variável política feita por J. Fitzgerald, D. Leblang e J. Teets (2014) para os debates nesse campo da política internacional. Tradicionalmente, as abordagens que discutem as causas das migrações focam, sobretudo, em fatores econômicos e também na rede de contatos do migrante no local de destino. Entretanto, recentemente, as condições políticas internas no país de destino têm se tornado uma variável chave para entender o fluxo internacional de pessoas.

Em seguida, no segundo tópico, além de apresentar a contribuição feita por J. Fitzgerald, D. Leblang e J. Teets (2014), iremos detalhar a composição do índice mencionado acima referente às políticas internas de concessão da cidadania. No terceiro tópico, apresentaremos uma perspectiva histórica das migrações internacionais no Brasil. Na quarta sessão, inserimos o caso brasileiro na codificação do índice para, então, compará-lo a outros países receptores de imigrantes.

Por fim, a partir dos resultados, foi possível questionar a validade da medida criada por J. Fitzgerald, D. Leblang e J. Teets (2014), visto que o Brasil apresenta um perfil de abertura política de acordo com os critérios elencados pelo índice, apesar de a legislação brasileira ter um caráter autoritário e conter sérias restrições à liberdade dos imigrantes.

\section{Teorias sobre as migrações internacionais}

A preocupação central de todas as teorias que discutem as migrações internacionais é tentar desvendar os motivos que levam os indivíduos a se deslocarem do local onde cresceram para viver em outro lugar. Diferentes abordagens foram desenvolvidas ao longo do tempo, algumas focam o aspecto individual da escolha e outras tratam de uma abordagem estrutural de fatores econômicos. É importante ressaltar que as correntes que iremos apresentar tratam das migrações voluntárias entre Estados, não se incluem as migrações forçadas, decorrentes de solicitação de refúgio, por exemplo.

A abordagem mais influente para explicar os fluxos migratórios voluntários tem sido a teoria neoclássica, que advoga a primazia da lógica econômica na decisão de migrar. Para os autores que trabalham nessa perspectiva, o migrante 
faz um cálculo estratégico em relação às diferenças de renda entre o país de origem e de destino. A questão salarial, portanto, seria o fator determinante para que o migrante deixe o seu país de origem (MASSEY et al., 1993, p. 434). Uma das principais referências para essa perspectiva foi o modelo estatístico criado por Michael Todaro, que procurava prever o fluxo migratório de centros rurais para urbanos por meio de duas variáveis explicativas: a diferença real de renda entre o campo/cidade e a probabilidade de conseguir um emprego no centro urbano (TODARO, 1969, p. 139). A utilização de métodos quantitativos nas teorias migratórias ofereceu uma contribuição importante para a realização de testes empíricos das hipóteses formuladas, porém não se pode esquecer que tais análises não levam em consideração o aspecto histórico, o que representa uma fragilidade no seu poder explicativo.

Apesar de o argumento econômico ser muito forte para justificar as decisões individuais, a teoria neoclássica vive um relativo declive em seu poder explicativo, visto que seus pressupostos se mostram inadequados às características dos processos migratórios atuais. O principal problema dessa abordagem é a expectativa de que houvesse um fluxo migratório consideravelmente alto de países do Sul Global para o Norte, visto que as diferenças entre os salários são muito altas. Porém, os números apontam em outra direção. Segundo o relatório das Nações Unidas sobre as migrações internacionais, os países do Norte receberam 53 milhões de imigrantes entre 1990 e 2013 (UNITED NATIONS, 2013, p. 1), o que representa um número relativo muito baixo quando comparado com a população mundial.

Em um estudo empírico analisando as causas das migrações internacionais em direção à União Europeia no período de 1980-2004, Hooghe et al. (2008) testaram as hipóteses da teoria neoclássica e encontraram resultados surpreendentes. Os dados mostraram que não houve significância estatística para o tamanho do Produto Interno Bruto (PIB) ou seu crescimento, ou seja, essas variáveis econômicas não explicam o fluxo migratório no modelo criado pelos autores. Porém, houve significância para uma demanda crescente no mercado de trabalho no país de destino (HOOGHE et al., 2008).

A segunda abordagem que iremos tratar é a teoria das redes, que atualmente tem um papel central nas análises sobre migrações internacionais. As redes migratórias podem ser definidas como o conjunto de relações interpessoais que articula aqueles que planejam emigrar com os compatriotas, parentes ou amigos já residentes no local de destino escolhido (ARANGO, 2003, p. 19). As redes representam uma forma de capital social, que permitem aos imigrantes 
ter acesso a oportunidades econômicas que não teriam de outra maneira, tal como o acesso ao mercado de trabalho. Portanto, as redes reduzem os riscos envolvidos no processo migratório e são os fatores determinantes na escolha do indivíduo partir de seu local de origem, conforme tal perspectiva de análise.

As pesquisas empíricas que incorporaram a existência das redes de parentes, amigos e compatriotas no local de destino como variável independente mostram uma forte influência desse fator na decisão dos indivíduos de emigrar. O trabalho de P. Pedersen, M. Pytlikova e N. Smith (2008) sobre o fluxo migratório para 27 países da OCDE (Organização para Cooperação e Desenvolvimento Econômico), no período de 1990 a 2000, traz fortes conclusões nesse sentido. As análises econométricas que mediram os efeitos das redes através do número de imigrantes da mesma nacionalidade que vivem no local de destino apresentaram um altíssimo efeito positivo para o estímulo do fluxo migratório (PEDERSEN; PYTLIKOVA; SMITH, 2008).

A terceira abordagem a ser tratada é a teoria do sistema mundo, que tem origem nas contribuições de Immanuel Wallerstein. Nessa perspectiva, ao contrário das anteriores, não se busca analisar a decisão racional dos indivíduos em torno da migração, mas sim explicar os fatores econômicos e sociais da estrutura do sistema que ocasionam os fluxos migratórios. Wallerstein (2006, p. 23) coloca que o moderno sistema mundo tem início no século XVI na Europa e nas Américas e depois se alastrou para o resto do globo. A teoria explica o fenômeno das migrações através da expansão do modo de produção capitalista para os países periféricos (WALLERSTEIN, 1996, p. 214). A desarticulação das formas tradicionais de vida na periferia criou um conjunto de pessoas dispostas a emigrar.

A teoria do sistema mundo no campo das migrações não se limita apenas ao pensamento de Wallerstein e recebeu diversas outras contribuições como a de Saskia Sassen (2014), que coloca as migrações atuais como uma forma de expulsão. Por exemplo, a autora destaca que terras tradicionalmente destinadas ao plantio de gêneros alimentícios básicos para o mercado interno no Brasil estão sendo substituídas por vastas plantações de soja, o que vem causando a expulsão de milhões de pequenos agricultores de suas terras (SASSEN, 2014, p. 82).

A vantagem dessa abordagem é a amplitude das análises, visto que há a tentativa de explicar todo o funcionamento do sistema econômico, político e social. Todavia, a generalização pode recair em reducionismo, prejudicando a capacidade analítica da teoria. De todo modo, as abordagens estruturais do fenômeno migratório são importantes contribuições para a área. Além da teoria do 
sistema mundo, cabe citar a teoria dos mercados de trabalho duais de Michael Piore (1979), que também explica as migrações internacionais através da macroestrutura, porém, para ele, o fator determinante dos fluxos seria uma demanda estrutural por mão de obra não qualificada nos países industrializados.

\section{A inserção da variável política no debate e o índice para medir as políticas de concessão de cidadania aos imigrantes}

O artigo produzido por J. Fitzgerald, D. Leblang e J. Teets "Defying the Law of Gravity - The Political Economy of International Migration", publicado em 2014, representa a inserção da variável política nos debates a respeito das causas das migrações internacionais, uma vez que verifica se o ambiente político no país de destino, em especial as políticas de concessão de cidadania, influencia a decisão do migrante. Também foi levado em consideração o nível de intolerância e hostilidade na sociedade contra grupos minoritários, medido através do apoio popular a partidos políticos de extrema direita.

Nessa perspectiva, o foco é na escolha individual de emigrar, assim como na teoria neoclássica e das redes, e não em fatores econômicos ou sociais da estrutura do sistema, que é o objeto da teoria do sistema mundo. Os autores realizaram um modelo estatístico de regressão linear com 50.928 observações de 18 países de destino e 170 países de origem durante o período de 1980-2006 (FITZGERALD; LEBLANG; TEETS, 2014, p. 415). Os dados foram obtidos através das agências nacionais de estatística, portanto se trata apenas das migrações legais.

A variável dependente é o fluxo migratório, por conseguinte o modelo testa quais variáveis explicativas influem para aumentar ou diminuir o número de imigrantes. Como variáveis de controle foram incluídas a diferença de renda entre os países de origem e destino, a distância, existência de redes, entre outras. A hipótese de trabalho é de que, mantendo as outras variáveis estáveis, as condições políticas no local de destino influenciam a decisão de emigrar. Para mensurar o ambiente político para os imigrantes em determinado país, os autores criaram um índice que mede a regulação das políticas de concessão de cidadania nos locais de destino.

Os resultados dos testes mostraram que o impacto das políticas de concessão de cidadania mais favoráveis é largamente positivo na decisão do migrante ao escolher um destino específico (FITZGERALD; LEBLANG; TEETS, 2014, p. 421). 
O poder explicativo da variável política se mostrou ainda maior do que se poderia inicialmente prever. Quando foram feitos testes para interagir o conjunto de direitos políticos dos imigrantes com a taxa de desemprego no país de destino se percebeu que, no momento em que os direitos políticos são limitados, o desemprego no local de destino tem um impacto negativo no fluxo migratório, ou seja, desestimula o fluxo. Porém, à medida que há o aumento nas garantias políticas em relação à cidadania dos imigrantes, o efeito negativo do desemprego sobre o fluxo migratório cai drasticamente (FITZGERALD; LEBLANG; TEETS, 2014, p. 421).

A vantagem da aplicação dos modelos estatísticos nas teorias das migrações é a possibilidade de fazer análises empíricas e teste de hipóteses, porém não se pode esquecer que todo modelo é uma simplificação da realidade e apresenta graus de incerteza nas suas previsões. Nosso trabalho não fará uma replicação dos resultados da regressão linear, mas sim a utilização do Índice de Concessão de Cidadania (ICC) para comparar a política migratória brasileira com outros países receptores de imigrantes.

O índice foi codificado a partir de quatro variáveis relacionadas à cidadania dos imigrantes: (i) o tempo necessário para que o imigrante possa solicitar residência permanente ou a naturalização, (ii) a possibilidade de ter uma dupla cidadania, (iii) a concessão de cidadania em função de nascimento no país (jus soli) e (iv) a necessidade de prestar um exame de idioma antes da concessão da cidadania no país escolhido (FITZGERALD; LEBLANG; TEETS, 2014, p. 411).

Dessa forma, o ICC foi elaborado pelos autores de maneira que o maior resultado possível de um país é oito, que significa uma política muito aberta, e o menor é zero, que seria uma política muito restritiva. A codificação é feita como se descreve a seguir: havendo possibilidade de acumular duas cidadanias, será atribuído 2 pontos ao país; em caso contrário, zero. Se houver previsão de concessão de cidadania pelo jus soli, serão somados mais 2 pontos à contagem; em caso contrário, zero. Se o país não fizer a exigência de prova de idioma para conceder a cidadania, serão somados mais 2; em caso contrário, zero. Em relação à quantidade de anos necessária para solicitar a residência permanente ou naturalização, adotou-se a seguinte forma: 0 a 5 anos, será atribuído 2; de 6 a 9 anos, será dado 1; e de 10 a 15 anos, será atribuído zero.

Dentro da categoria referente ao tempo necessário para a concessão da cidadania, mede-se também o tempo que o imigrante é obrigado a esperar para que tenha acesso pleno aos direitos políticos. Considerando que, em alguns países, o imigrante residente não pode votar, a única forma de ter acesso à participação 
eleitoral é através da naturalização, o que se torna de fundamental importância, visto que frequentemente imigrantes precisam se articular politicamente para tratar de questões sensíveis àquela comunidade e que, sem o direito ao voto, é mais difícil conseguir apoio institucional.

Além do tempo de residência, alguns países solicitam um exame de idioma, a fim de verificar se o imigrante tem o domínio da língua falada naquele país. Em alguns casos, a prova pode ser um obstáculo para o imigrante conseguir a cidadania e, consequentemente, os direitos políticos de forma plena. (FITZGERALD; LEBLANG; TEETS, 2014, p. 412).

Em alguns lugares, a possibilidade de cumular duas cidadanias distintas é proibida, de forma que, para adquirir a nacionalidade no local onde o imigrante reside, ele precisa abdicar da nacionalidade do seu país de origem. Para muitos indivíduos, isso pode ser um problema, já que significa abdicar também de vantagens econômicas, tais como questões de herança, possibilidade de adquirir propriedade ou investimentos ou mesmo o acesso ao mercado de trabalho, em caso de retorno ao país de origem.

Por fim, há a questão da possibilidade de receber cidadania em razão do nascimento no país (jus soli), que é importante, sobretudo, para os filhos daqueles que migraram. Para garantir uma integração maior da comunidade de imigrantes com o país de acolhimento, é preciso que seja facilitado o processo de concessão de direitos políticos, especialmente em relação àqueles indivíduos que nascem no país.

\section{Perspectiva histórica das migrações internacionais no Brasil}

Em termos gerais, a complexidade do processo de concessão de cidadania tende a depender não só de fatores socioculturais, mas, talvez principalmente, da conjuntura macroestrutural do país receptor (BRITO, 2000). Pode-se afirmar que, no Brasil, a variação dos fluxos migratórios, em grande parte, operou de acordo com o grau de concentração das bases produtivas da economia nacional.

Os períodos de maior receptividade aos imigrantes coincidiram com as décadas de concentração da mão de obra no setor primário, responsável por carregar o projeto desenvolvimentista do século XIX. De acordo com tal tendência, a entrada massiva de trabalhadores europeus compôs um "estoque de imigrantes" que representava cerca de $6,16 \%$ da população nacional até o início do século XX, 
período que marcou o declínio progressivo da entrada de estrangeiros no país (PATARRA, 2005, p. 28).

A expansão das fronteiras agrícolas e o rápido processo de urbanização alteraram não só a dinâmica demográfica das migrações internas, mas a disposição do país para manter o padrão anterior de acolhimento aos estrangeiros (BRITO, 2000, p. 10). A partir da década de 1940, o conjunto de imigrantes do Brasil passa a decrescer em números absolutos, atingindo, nos anos 1980, a proporção de apenas 0,77\% do contingente populacional do país - que, por sua vez, havia dobrado em relação aos anos 1940.

O período, ao mesmo tempo em que sinalizou o início das transformações econômicas, políticas, sociais e demográficas que definiram as características do processo mais recente de globalização, também foi marcado pelo agravamento da situação econômica brasileira, com o ápice do crescimento de sua dívida externa, e pela compressão dos índices de emprego. Um dos maiores marcos do endurecimento da política brasileira de recepção aos imigrantes surge com a instituição dos critérios restritivos de concessão de cidadania incorporados pelo Estatuto do Estrangeiro, sancionado no início da década de 1980.

Apesar de agilizar a normatização sobre a integração dos imigrantes, a rigidez das regras adotadas pelo documento refletiu a preocupação do Estado em proteger a mão de obra doméstica brasileira e desonerar os gastos públicos com contingentes estrangeiros (PATARRA, 2008, p. 30). Segundo Neide Patarra, a institucionalização desse conjunto de regras caracteriza o Brasil “como um dos países mais restritivos quanto à imigração” (2005, p. 31). Para a autora, tão grave quanto a complexidade burocrática da concessão de cidadania, a integração dos imigrantes não documentados denota como essa rigidez manifesta-se na realidade social do estrato de estrangeiros: sem o cumprimento dos vários quesitos para legalidade, os estrangeiros são privados do acesso a serviços públicos básicos, como educação e saúde (PATARRA, 2005).

Portanto, compreender a dimensão política atual do processo de concessão da cidadania no Brasil depende em grande parte da reflexão sobre as transformações que o processo mundial de reestruturação produtiva imputou sobre as novas dinâmicas de mobilidade de capital e populacional no mundo (BAENINGER, 2012, p. 9). Apesar de as estratégias políticas e econômicas de inserção internacional do Brasil no contexto globalizado não destoarem do restante da América Latina, o regionalismo e o incentivo aos investimentos transnacionais não modificaram a rigidez de sua política de acolhimento aos estrangeiros (PATARRA, 2008). 
Essas mudanças, em geral, destacaram a importância da institucionalização das políticas nacionais de concessão de cidadania nas agendas públicas, especialmente a partir dos anos 1980. Em termos procedimentais, o grau de abertura política do Brasil nem sempre destoa da maioria dos países receptores de imigrantes no mundo. Nesse sentido, as próximas seções discutem em que medida a perspectiva institucionalista do índice de J. Fitzgerald, D. Leblang e J. Teets (2014) capta a realidade do processo de integração dos imigrantes e qual é o posicionamento o Brasil, em comparação a outros países receptores.

\section{O Brasil em perspectiva comparada}

Apresentaremos agora a tabela e o gráfico comparativo com os resultados do índice que avalia as condições internas referentes às políticas de concessão de nacionalidade em 23 países, incluindo o Brasil. Os dados utilizados são provenientes do trabalho feito por J. Fitzgerald, D. Leblang e J. Teets (2014), exceto o Brasil, cuja codificação foi elaborada por nós.

No banco de dados dos autores, a composição do índice é feita ao longo do tempo, de modo que um mesmo país é codificado desde cerca de 1970 até 2005, de acordo com a disponibilidade de dados. Na nossa análise, utilizamos a codificação dos países no ano de 2005 (mais recente) e inserimos o Brasil, a fim de comparar como a política brasileira de concessão de cidadania se comporta quando comparada a outros locais de destino. Outro objetivo do nosso trabalho foi, também, discutir a validade do índice, ou seja, se ele de fato mede o que se propõe a representar.

A composição do índice foi feita conforme detalhamos no segundo tópico. A maior pontuação possível é 8, que significa o maior grau de abertura, e o menor resultado possível é zero, que significa o maior grau de restrição. De acordo com as classificações do índice, o Brasil pode ser considerado um dos países mais abertos à integração dos imigrantes. Analisando um a um os componentes do ICC, observamos que as instituições brasileiras, (i) apesar de exigirem a prova de idioma - 0 pontos, (ii) permitem, facilmente, o acúmulo de mais de uma cidadania - 2 pontos; (iii) garantem o direito de jus soli - 2 pontos; (iv) e estabelecem como apenas 4 anos o tempo mínimo para solicitação de residência fixa ou de naturalização - 2 pontos. Portanto, a legislação do país é suficiente para que o índice atribua o valor 6 ao caso brasileiro. 
Tabela 1 - Composição do Índice de Concessão de Cidadania

\begin{tabular}{|c|c|c|c|c|c|}
\hline \multirow[b]{2}{*}{ País } & \multicolumn{4}{|c|}{ Critérios } & \multirow{2}{*}{$\begin{array}{c}\text { Resultado } \\
\text { final }\end{array}$} \\
\hline & Jus soli & $\begin{array}{c}\text { Residência } \\
\text { permanente (anos) }\end{array}$ & $\begin{array}{c}\text { Dupla } \\
\text { cidadania }\end{array}$ & $\begin{array}{c}\text { Exame de } \\
\text { idioma }\end{array}$ & \\
\hline Irlanda & $\operatorname{sim}$ & 5 & $\operatorname{sim}$ & não & 8 \\
\hline Austrália & $\operatorname{sim}$ & 2 & $\operatorname{sim}$ & $\operatorname{sim}$ & 6 \\
\hline Bélgica & não & 3 & $\operatorname{sim}$ & não & 6 \\
\hline Brasil & $\operatorname{sim}$ & 4 & $\operatorname{sim}$ & $\operatorname{sim}$ & 6 \\
\hline Canada & $\operatorname{sim}$ & 3 & $\operatorname{sim}$ & $\operatorname{sim}$ & 6 \\
\hline Estados Unidos & $\operatorname{sim}$ & 5 & $\operatorname{sim}$ & $\operatorname{sim}$ & 6 \\
\hline França & $\operatorname{sim}$ & 5 & $\operatorname{sim}$ & $\operatorname{sim}$ & 6 \\
\hline Nova Zelândia & $\operatorname{sim}$ & 5 & $\operatorname{sim}$ & $\operatorname{sim}$ & 6 \\
\hline Reino Unido & $\operatorname{sim}$ & 5 & $\operatorname{sim}$ & $\operatorname{sim}$ & 6 \\
\hline Suécia & não & 5 & $\operatorname{sim}$ & não & 6 \\
\hline Alemanha & $\operatorname{sim}$ & 8 & $\operatorname{sim}$ & $\operatorname{sim}$ & 5 \\
\hline Grécia & não & 10 & $\operatorname{sim}$ & não & 4 \\
\hline Holanda & $\operatorname{sim}$ & 5 & não & não & 4 \\
\hline Itália & não & 10 & $\operatorname{sim}$ & não & 4 \\
\hline Japão & não & 5 & não & não & 4 \\
\hline Portugal & $\operatorname{sim}$ & 10 & $\operatorname{sim}$ & $\operatorname{sim}$ & 4 \\
\hline Suíça & não & 12 & $\operatorname{sim}$ & não & 4 \\
\hline Finlândia & não & 6 & $\operatorname{sim}$ & $\operatorname{sim}$ & 3 \\
\hline Noruega & não & 7 & não & não & 3 \\
\hline Luxemburgo & não & 5 & não & $\operatorname{sim}$ & 2 \\
\hline Dinamarca & não & 9 & não & $\operatorname{sim}$ & 1 \\
\hline Áustria & não & 10 & não & $\operatorname{sim}$ & 0 \\
\hline Espanha & não & 10 & não & $\operatorname{sim}$ & $\mathbf{0}$ \\
\hline
\end{tabular}

Fonte: Fitzgerald; Leblang; Teets, 2014. Exceto Brasil - elaboração própria. 


\section{Gráfico 1 - Índice de Concessão de Cidadania}

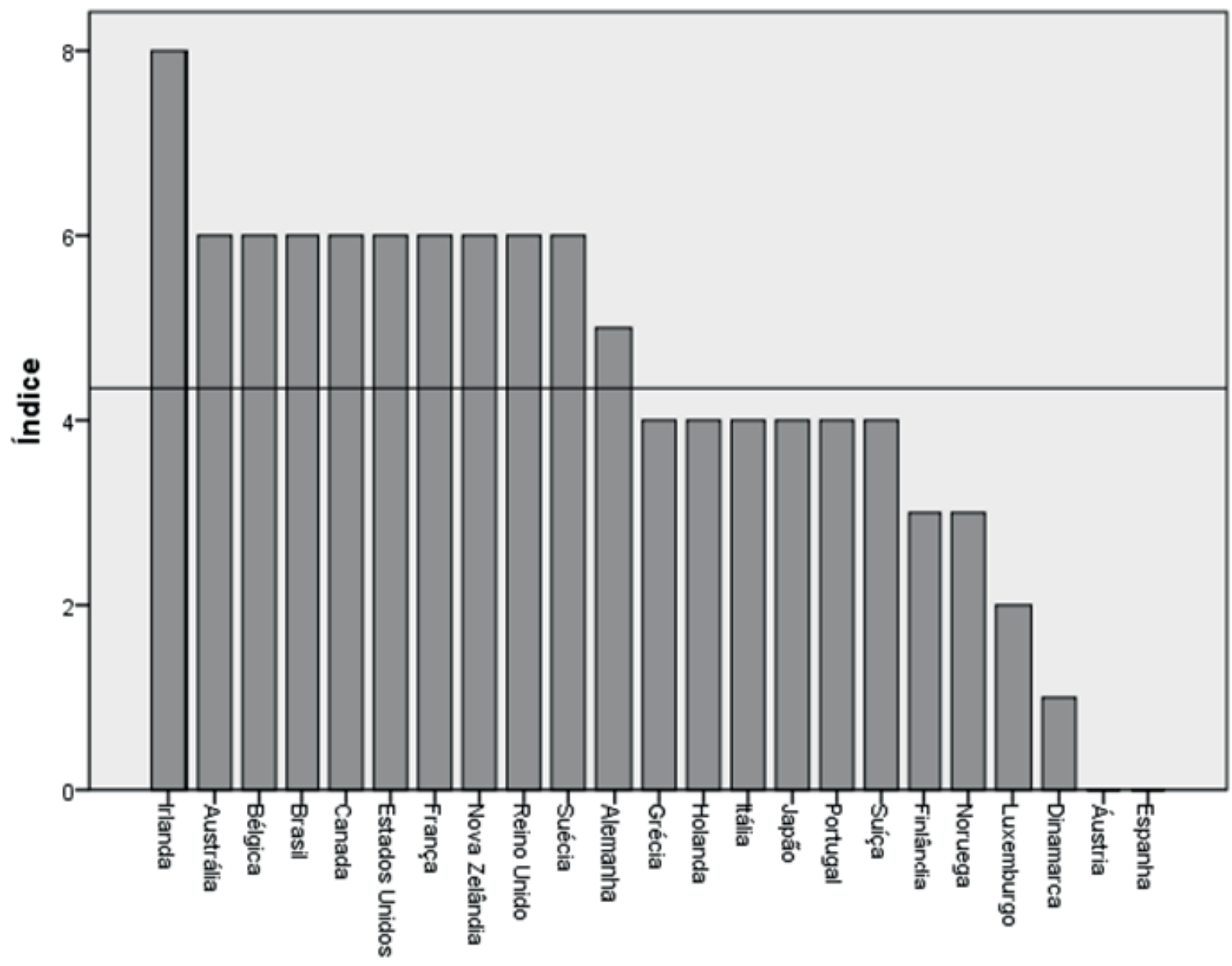

Paises

Fonte: Fitzgerald; Leblang; Teets, 2014. Exceto Brasil - elaboração própria.

A partir da análise do gráfico e da tabela, percebe-se que a Irlanda é o país cuja política de concessão de cidadania é mais favorável, enquanto que a Áustria e a Espanha aparecem no fim da lista com as políticas mais restritivas. A linha horizontal do gráfico representa a média, que foi de 4,35. É possível perceber visualmente que a maior parte dos casos não se distancia da média de forma acentuada.

É preciso, porém, fazer uma ressalva em relação ao caso espanhol, que em sua lei geral proíbe o gozo da dupla nacionalidade, todavia faz uma exceção aos imigrantes provenientes das ex-colônias da América Latina, que podem manter sua cidadania anterior (ALEINIKOFF; KLUSMEYER, 2011, p. 28).

Recentemente, a Espanha passou por um processo conturbado de reforma do marco legal que disciplina a imigração no país. Até 1999, a legislação regulava a imigração não comunitária como um fenômeno temporalmente delimitado de caráter puramente laboral, o que dificultava o processo de nacionalização dos estrangeiros e sua integração à comunidade. Em 2000, foi promulgada a "Lei sobre 
os Direitos e Liberdades dos Estrangeiros na Espanha e sua Integração Social”, que ampliou sobremaneira o rol de garantias básicas gozados pelos imigrantes residentes. Contudo, no mesmo ano, o Partido Popular (PP), que possui uma plataforma de centro-direita, conseguiu a maioria absoluta dos assentos no parlamento e fez uma reforma da legislação, tornando-a mais restritiva. O Tribunal Supremo Espanhol declarou inconstitucional parte das alterações e uma nova (e última) legislação foi editada em 2003, mantendo alguns dos avanços em relação ao acesso à justiça e integração social dos imigrantes (MONTIJANO, 2008, p. 85).

Apesar das mudanças em prol de um regime menos restritivo, a Espanha ainda continua categorizada com a pior classificação possível no índice de concessão de cidadania no ano de 2005. O que pode demonstrar a incapacidade do indicador de ser sensível a mudanças mais sutis no ambiente político encontrado por estrangeiros no país de destino.

Em relação ao caso da França, as principais mudanças ocorrem a partir do processo de descolonização, quando o país passa a receber grandes levas de imigrantes de suas antigas colônias no Magrebe. Desde a década de 1980, o governo francês promove endurecimentos nas leis de concessão de nacionalidade para imigrantes. Um exemplo foi a suspensão, entre 1993 e 1998, do direito automático de jus soli, e um jovem nascido na França de pais imigrantes deveria manifestar sua vontade de se tornar francês.

Grande parte das leis está contida no Código Civil que, apesar de ter sido promulgado em 1804, foi amplamente modificado ao longo dos anos ${ }^{6}$; boa parte das leis sobre concessão vive em constante reformulação, principalmente a regulamentação das normas. Vale destacar a recente criação de um novo tipo de crime na França, que ficou conhecido por "delito de solidariedade", que punia com reclusão os cidadãos franceses que ajudassem migrantes sem documentos.

A prova de línguas demanda também um conhecimento de história, de cultura e de civilização francesa, sendo vista como uma forma de "adesão aos valores da República”, em uma prova realizada com uma entrevista - segundo o decreto n 2011-1265, de 11 de outubro de 2011 (FRANÇA, 2011). De fato, muitos países da África e Ásia possuem o francês como língua oficial, herança do período colonial, desse modo, a prova de línguas somente seria uma facilidade para imigrantes dessas regiões. Há, portanto, um alto grau de subjetividade atrelada à

6 O Ministério do Interior Francês fornece uma lista com a série histórica das principais mudanças, que pode ser consultada no seguinte endereço: < http://www.immigration.interieur.gouv.fr/Accueil-et-accompagnement/Lacces-a-la-nationalite-francaise/Historique-du-droit-de-la-nationalite-francaise > . Acesso em 16 de março de 2016. 
concessão de nacionalidade para imigrantes. Outro exemplo disso, e que também pode afetar o índice, diz respeito à experiência profissional, que será avaliada sob critérios não divulgados no momento da demanda da naturalização (Circular $\mathrm{n}^{\circ}$ NORINTK1207286C).

No Reino Unido, alguns pontos são parecidos com a França. O British Nationality Act, de 1981, estabelece as condições de concessão de cidadania. Em relação ao jus soli, a lei estabelece que somente será concedida a nacionalidade ao filho se ao menos um dos pais for britânico. Outro ponto importante sobre a lei do Reino Unido diz respeito à integração dos membros do Commonwealth: o direito à residência só poderá ser concedido para uma pessoa nascida depois de 1983 se ela possuir a cidadania britânica - seção 4C do British Nationality Act.

Há também uma prova para concessão de nacionalidade, além da prova de língua inglesa, conhecida como "Teste para viver no Reino Unido" e é amplamente criticada por seus aspectos subjetivos (BROOKS, 2013). Finalmente, o governo britânico tem também promovido uma série de medidas de recrudescimento das concessões que, como na França, não afetam o essencial da lei, mas criam condições adversas aos estrangeiros que demandam a nacionalidade.

Apesar dos casos da França e Reino Unido, a análise de Marc Howard (2005) a partir do índice mostra que a tendência geral dos países europeus se deu no sentido de liberalização das políticas de concessão de nacionalidade. Nota-se que a maior flexibilização foi referente à política de dupla nacionalidade; países como a Suécia, a Finlândia e a Holanda passaram a ter uma maior abertura nesse sentido. No caso holandês, apesar da lei geral ainda proibir a dupla cidadania, houve o acréscimo recente de várias exceções à proibição que caracterizam uma flexibilização. No entanto, o caso mais paradigmático é o da Alemanha, que, na sua última reforma legal, passou a conceder a nacionalidade também por nascimento no território alemão (jus soli), além de reduzir o tempo necessário para requerer a residência permanente de 15 para 8 anos (HOWARD, 2005, p. 712).

O padrão que mais se repete na tabela é o de países que aceitam o jus soli, que permitem a dupla cidadania e cujo tempo de residência necessário para requerer a nacionalização é igual ou inferior a cinco anos; além da exigência de uma prova de idioma durante tal processo. Do total de 23 países incluídos na análise, sete se enquadram neste perfil: Austrália, Canada, Estados Unidos, França, Nova Zelândia, Reino Unido e o Brasil.

Segundo J. Fitzgerald, D. Leblang e J. Teets (2014), existe uma forte correlação estatística entre uma elevada pontuação no índice de concessão de cidadania e o 
fluxo migratório. Os resultados do trabalho mostram que somente a permissão de cumular duas nacionalidades aumenta o fluxo em $68 \%$; os países que permitem o jus soli têm um aumento de $32 \%$ no número de imigrantes; países sem exigência de prova de idioma aumentam o fluxo em $43 \%$ e, à medida que se aumenta o tempo necessário para requerer a residência permanente, há um decréscimo de $14 \%$ no fluxo migratório. Os resultados estatísticos para a medida do índice com essas quatro variáveis juntas também foram significativos e representaram um aumento na faixa dos $23 \%$ (FITZGERALD; LEBLANG; TEETS, 2014, p. 420).

A respeito do Brasil, percebe-se que o país está junto do grupo que possui uma política mais aberta, conforme os critérios definidos pelo índice. No entanto, existem questões mais sutis no tratamento aos imigrantes no Brasil que passam despercebidas em uma análise mais superficial. Historicamente, a política migratória brasileira, em sua origem, foi flexível, já que, especialmente durante o Império, a vontade do Estado era atrair mão de obra assalariada proveniente de países europeus. Segundo Guido Soares, "nos jovens Estados da América, em particular no Brasil, a tradição sempre fora de considerar-se o estrangeiro em pé de igualdade com os nacionais" (SOARES, 2004, p. 184).

Contudo, a lei em vigor que rege a política referente à concessão de nacionalidade no Brasil, ainda corresponde ao Estatuto do Estrangeiro (Lei $6.815 / 1980$ ), elaborado durante a ditatura militar e que adota, além da proteção ao mercado de trabalho doméstico, uma perspectiva de prioridade à segurança nacional (Art. $2^{\circ}$ ). Atualmente, a legislação dos países que recebem imigrantes passa por uma tensão constante entre a proteção dos direitos humanos e questões relacionadas à segurança nacional (PATARRA, 2011, p. 156). Entretanto, essa tensão não é tão importante no Brasil, visto que predomina na legislação nacional o viés da segurança nacional, considerando o contexto da ditadura civil-militar em que a lei 6.815/1980 foi criada.

Quando se trata das condições políticas internas encontradas por imigrantes no Brasil, uma análise apenas com as quatro variáveis elencadas no índice de concessão de nacionalidade pode levar a um engano. O artigo 107 da lei 6.815/1980 proíbe expressamente que o estrangeiro se envolva em qualquer atividade de natureza política no Brasil, inclusive a lei veda que o estrangeiro organize desfiles, passeatas, comícios ou reuniões que envolvam qualquer natureza política.

Outros dispositivos do Estatuto do Estrangeiro também chamam atenção por seu caráter autoritário, como, por exemplo, a vedação à participação dos estrangeiros em sindicatos (artigo 106, VII). Além disso, as entidades ou associações 
de estrangeiros com fins culturais, religiosos ou beneficentes, caso tenham mais da metade de seus membros com nacionalidade estrangeira, precisam pedir autorização ao Ministério da Justiça para entrar em funcionamento (artigo 108, parágrafo único).

Apesar do artigo cinco, caput da Constituição Federal, mencionar expressamente os estrangeiros residentes no país ao garantir as liberdades e garantias fundamentais, o Supremo Tribunal Federal ainda não se pronunciou sobre a constitucionalidade (ou recepção/revogação) dos dispositivos da lei mencionada acima. Portanto, a princípio, tais dispositivos continuam em vigor. A própria Constituição promulgada em 1988 não apresentou grandes avanços em relação aos direitos políticos dos imigrantes no país - o artigo 14 , $\S 2^{\circ}$ traz uma vedação expressa ao exercício do direito ao voto por parte de estrangeiros residentes de forma permanente no país. Para votar, é necessário que o imigrante se submeta ao processo de aquisição da nacionalidade brasileira, com exceção do imigrante de nacionalidade portuguesa.

A questão do direito ao voto é especialmente sensível, visto que é a garantia básica de inserção dos indivíduos dentro da dinâmica política interna de um país. Sem o voto, as comunidades de imigrantes têm pouco apelo político frente aos representantes e enfrentam barreiras desproporcionais ao tentar garantir seus interesses. Outros países da América Latina, como Argentina, Colômbia e Peru garantem aos imigrantes o direito ao voto, mesmo que apenas nas eleições locais.

O Brasil é um país que favorece a inserção de imigrantes de alta renda e qualificados, conforme deixa expresso o artigo 112, $V$ da lei 6.815/1980, que reduz o tempo necessário para requerer a nacionalidade brasileira para empresários dedicados à atividade industrial ou agrícola, proprietários de ações ou imóveis a partir de um valor determinado. No entanto, os migrantes que chegam ao Brasil para ocupar postos de trabalho de menor remuneração sofrem com preconceito e discriminação, sobretudo racial, como o caso dos imigrantes haitianos que se deslocaram para o Brasil na esteira dos eventos que ocorreram na última década. No Paraná, o Ministério Público do Trabalho recebeu e encaminhou denúncias de racismo e agressões contra imigrantes haitianos no próprio local de trabalho (MPT, 2014).

Apesar de a legislação brasileira continuar com um viés autoritário, alguns avanços foram efetuados na tentativa de trazer dignidade para os estrangeiros que vivem no país. Por exemplo, em 2009, o Brasil assinou a Convenção Internacional sobre os Direitos dos Trabalhadores Migrantes e Membros de suas Famílias, que garante uma série de direitos trabalhistas básicos para os imigrantes. A assinatura 
da convenção serviu de base para a retórica brasileira em fóruns internacionais, que buscava uma defesa mais ampla dos direitos humanos (REIS, 2011, p. 63).

Em 2014, foi realizada a Conferência Nacional sobre Migrações e Refúgio no Brasil, que, entre outros temas, discutiu as condições políticas internas para imigrantes no país. O principal eixo de reinvindicação por parte dos migrantes foi a necessidade de assegurar a igualdade jurídica, o pleno acesso à justiça, a efetividade de liberdades e garantias fundamentais e o tratamento igualitário entre brasileiros e estrangeiros.

Recentemente, outro importante esforço foi feito para a elaboração de um Anteprojeto de Lei para reformar o Estatuto do Estrangeiro (Lei 6.815/1980) e tornar a legislação compatível com a Constituição Federal de 1988. Uma comissão de especialistas foi designada para desenvolver o anteprojeto, que ficou pronto em março de 2014. A principal inovação foi a mudança de paradigma da segurança nacional para a proteção dos direitos humanos, adequando a legislação interna brasileira com os tratados internacionais referentes ao tema assinados pelo Brasil.

Além da mudança no referencial jurídico no qual a legislação se apoia, o anteprojeto também prevê uma grande transformação na burocracia nacional mobilizada para atender os imigrantes. Por exemplo, atualmente, o principal órgão competente para atender os migrantes é a Polícia Federal, inclusive em casos de solicitação de refúgio quando o sujeito entra sem documentos no país, o que gera desconforto por parte dos indivíduos que precisam regularizar sua situação. Apesar de debates promissores com a sociedade civil, o novo Anteprojeto ainda precisa ser capaz de construir uma ampla base de apoio entre os congressistas a fim de ser aprovado no parlamento.

\section{Questionamentos sobre a validade do índice de concessão de cidadania}

Diante da análise comparativa apresentada acima, percebe-se que o indicador criado por J. Fitzgerald, D. Leblang e J. Teets (2014) para avaliar as condições políticas internas encontradas por imigrantes apresenta algumas fragilidades. Primeiramente, considerando que o voto representa o direito político mais básico, a ausência dessa variável causa uma distorção na medida.

Há o argumento de que os autores inseriram os direitos políticos, inclusive o sufrágio, de forma implícita na variável que mede o tempo necessário para 
requerer a naturalização. Todavia, muitos imigrantes não querem adquirir a nacionalidade do local onde vivem, muitas vezes em virtude da proibição de ter a dupla cidadania, no país de origem ou de destino. Portanto, há uma quantidade considerável de imigrantes com residência permanente que ficam em situação vulnerável em relação à garantia de seus direitos políticos.

Com as variáveis atualmente incluídas no índice, é possível avaliar as condições políticas internas para o imigrante qualificado ou de alta renda que pretende se nacionalizar e entra regularizado no país de destino. Todavia, não é possível afirmar que o índice analisa as condições políticas internas para os imigrantes de forma geral, visto que a maior parte dos imigrantes é pobre, foge da fome e de guerras e tenta entrar no país de destino sem documentos.

As prioridades políticas de um imigrante não regularizado em relação ao país de destino talvez sejam muito diferentes das elencadas no indicador. Apesar de, inegavelmente, a dupla cidadania e o jus soli serem importantes, o acesso a serviços básicos de saúde é essencial. Existem países que permitem aos imigrantes utilizarem serviços médicos públicos, outros não. Entretanto, tal diferença não foi captada na medida criada por J. Fitzgerald, D. Leblang e J. Teets (2014), o que demonstra uma fraqueza do indicador.

Além do mais, em diversos casos, como no Brasil ou nos Estados Unidos, o imigrante que entra ilegalmente no país não pode ser regularizado pela via ordinária, ele só pode receber documentos oficiais se houver a promulgação de uma lei específica que estabeleça a anistia. Portanto, o tempo necessário para requerer a nacionalidade, a dupla cidadania e o exame de idioma se tornam critérios irrelevantes para as pessoas que entraram cladestinamente nesses países, visto que elas nunca terão acesso a tais dispositivos legais.

Metodologicamente, medir algo envolve comparar aspectos da realidade com um standard, sejam capacidades, categorias ou quantidades (KING; EPSTEIN, 2002, p. 81). Para que uma medida seja uma representação adequada da realidade, é necessário preencher dois requisitos. O primeiro é a confiança, que significa a possibilidade de replicar a mensuração, reproduzindo o mesmo valor (independente de ser correto ou não). Ou seja, é a necessidade de que, ao medir um fenômeno várias vezes durante determinado tempo, da mesma forma e com o mesmo padrão de medida, obtenha-se um resultado igual em todas as medições, independente de quem as realize. Um indicador não confiável será um problema para a pesquisa, visto que a amostra será enviesada. A princípio, observa-se que não há nenhum problema de confiança na medida do índice de concessão de cidadania elaborado por J. Fitzgerald, D. Leblang e J. Teets (2014). 
O segundo requisito metodológico para que uma medida seja adequada é a validade, que consiste em medir aquilo que se acredita estar medindo (KING; KEOHANE; VERBA, 1994, p. 25). A validade se refere à correspondência entre o instrumento empírico de mensuração e o conceito teórico que deu origem à pesquisa. Naturalmente, sempre haverá graus de incerteza durante o processo de investigação, especialmente nas ciências humanas. Porém, existem medidas que claramente não correspondem ao que se propõe a analisar e tal parece ser o caso do índice de concessão de cidadania concebido por J. Fitzgerald, D. Leblang e J. Teets (2014) visto que as condições políticas internas encontradas por imigrantes são muito mais amplas que as variáveis inseridas no indicador.

A questão central, no entanto, pode ser a da especificação do conceito que está sendo medido. Se utilizarmos o indicador para discutir apenas o fluxo migratório de indivíduos qualificados profissionalmente ou de alta renda, a medida parece ganhar poder explicativo. Por exemplo, conforme reportamos acima, a tendência dos países europeus, de acordo com o índice, é de flexibilização na concessão de nacionalidade, o que pode parecer contra intuitivo, se consideramos a política migratória europeia de forma abrangente. Porém, essa disposição possivelmente pode ser explicada através da tentativa de governos europeus de atrair mão de obra qualificada. Portanto, há indicações de que essa poderia ser uma interpretação possível para os resultados, mas apenas novos testes empíricos poderiam confirmar tais conjecturas.

\section{Conclusões}

A análise comparada da política migratória brasileira com países que são tradicionalmente destino de imigrantes ficou prejudicada em virtude das deficiências apresentadas pelo indicador utilizado. Conforme demonstrado acima, o Brasil aparece com uma classificação mais próxima da abertura política em relação aos estrangeiros, todavia a legislação atual, o Estatuto do Estrangeiro (Lei 6.815/1980), evidencia um caráter autoritário e restritivo em relação às liberdades políticas mais essenciais da vida em sociedade.

Portanto, a medida criada por J. Fitzgerald, D. Leblang e J. Teets (2014) não é capaz de ser um parâmetro adequado para medir as condições políticas internas encontradas pelos migrantes de forma geral. Todavia, há indicativos de que o índice pode servir para comparações em relação às políticas nacionais de atração 
de mão de obra qualificada, visto que as variáveis utilizadas são representativas dos interesses desse grupo de imigrantes.

Em pesquisas futuras, caso haja o interesse em mensurar o ambiente político no país de destino para os indivíduos em geral, nós trazemos algumas sugestões para a criação de um novo indicador. Primeiramente, a possibilidade de participar das eleições, ainda que restrito à esfera municipal, deveria ser acrescentada como variável, já que não há direito político mais básico que o voto.

Em segundo lugar, pode-se contabilizar se a legislação específica que regula o processo migratório garante as salvaguardas legais presentes na Constituição (ou equivalente) para o estrangeiro. Ou seja, em caso de sofrer algum inquérito policial ou processo judicial, se o imigrante tem a garantia do devido processo legal, contraditório, ampla defesa e outros direitos processuais básicos.

A possibilidade de regularização do estrangeiro que entrou ilegalmente no país também se mostra essencial para a composição de um novo indicador com o objetivo de mensurar as condições políticas internas para os imigrantes de forma mais precisa. Conforme dito anteriormente, essa informação é importante para que o tempo necessário para requerer a nacionalização, a possibilidade de requerer dupla cidadania e o exame de idioma se tornem variáveis relevantes para todos os contextos.

Por fim, sugerimos que a permissão legal (ou ausência de proibição) para o imigrante residente utilizar serviços básicos de saúde e educação, disponíveis para os nacionais, também seja incluída como variável para medir o grau de abertura ou restrição em termos migratórios. Se condições políticas internas no local de destino influenciam a decisão de indivíduos escolherem um país em detrimento de outro, certamente o acesso a serviços públicos essenciais é um fator determinante nessa decisão.

É imprescindível que as novas pesquisas, visando oferecer uma contribuição para o debate sobre as migrações internacionais, tentem incluir medidas que sejam representativas da população de migrantes de forma geral. Para tanto, acreditamos que nossas sugestões podem contribuir para a criação de um novo indicador, relacionadas às condições políticas internas encontradas por imigrantes no país de destino, mais adequado à realidade vivida por todos aqueles que se deslocam.

Sabemos da dificuldade em realizar estudos empíricos que contabilizem todos os imigrantes, inclusive os sem documentos, visto que normalmente não há dados oficiais confiáveis sobre todos os estrangeiros residentes. Porém, é possível encontrar alternativas para fazer estimativas a fim de incluir todos os indivíduos. 
Afinal, as teorias sobre as migrações internacionais buscam desvendar quais as causas que são determinantes para o fluxo de pessoas em geral, e não de apenas uma parcela dessa população.

\section{Referências}

ALEINIKOFF, Alexander; KLUSMEYER, Douglas. Citizenship Policies for an Age of Migration. Washington: Carnegie Endowment, 2011.

ARANGO, Joaquín. La Explicación Teórica de las Migraciones: Luz y Sombra. Migración y Desarrollo, n. 1, 2003, p. 1-30. Disponível em http://pendientedemigracion.ucm. es/info/gemi/descargas/articulos/42ARANGO_La_Explicacion_Teorica_Migraciones_ Luces_Sombras.pdf. Acesso em 10/03/2016.

BAENINGER, Rosana. O Brasil na rota das migrações latino-americanas. In BAENINGER, R. (org.) Imigração boliviana no Brasil, Campinas: Núcleo de Estudos de PopulaçãoNepo/Unicamp, 2012, p. 9-18.

BRASIL. Lei $n^{\circ}$ 6.815, de 19 de agosto de 1980. Define a situação jurídica do estrangeiro no Brasil, cria o Conselho Nacional de Imigração. Brasília, DF, 1980.

BRITO, Fausto. Brasil, final de século: a transição para um novo padrão migratório. Encontro Nacional de Estudos Populacionais, vol. 12, 2000. Disponível em http:// www.abep.nepo.unicamp.br/docs/anais/pdf/2000/Todos/Brasil, \%20Final\%20de \% 20 século \% 20- \% 20A \% 20Transição \% 20Para \%20Um....pdf. Acesso em 04/03/2016.

BROOKS, Thom. The 'life in the United Kingdom' citizenship test: is it unfit for purpose? Durham: Durham University, 2013. Disponível em http://thombrooks.info/Brooks_ citizenship_test_report.pdf. Acesso em 07/03/2016.

CONFERÊNCIA NACIONAL SOBRE MIGRAÇÕES E REFÚGIO. Caderno de Propostas. Brasília. 2014. Disponível em http://reporterbrasil.org.br/documentos/comigrar. pdf. Acesso em 10/03/2016.

FITZGERALD, Jennifer; LEBLANG, David; TEETS, Jessica. Defying the Law of Gravity: The Political Economy of International Migration. World Politics, vol. 66, n. 3, 2014, p. 406-445.

FRANÇA. Decreto n²011-1265, de 11 de outubro de 2011. Relatif au niveau de connaissance de la langue française requis des postulants à la nationalité française. Jounal Officiel de la République Française, $\mathrm{n}^{\circ} 237$ de Outubro de 2011, texto $\mathrm{n}^{\circ}$ 13. Disponível em: $<$ https://www.legifrance.gouv.fr/affichTexte.do;jsessionid $=$ ? cidTexte = JORFTEXT0 $00024659084 \&$ dateTexte $=$ \&oldAction $=$ rechJO\&categorieLien $=\mathrm{id}>$. Disponibilidade $16 / 03 / 2016$. 
FRANÇA. Circular nº NORINTK1207286C, de 16 de outubro de 2012. Procédure d'accès à la nationalité française. Disponível em: < http://circulaire.legifrance.gouv.fr/ pdf/2012/10/cir_35948.pdf > . Disponibilidade 16/03/2016.

HOOGHE, Marc; TRAPPERS, Ann; MEULEMAN, Bart; REESKENS, Tim. Migration to European Countries: A Structural Explanation of Patterns, 1980-2004. International Migration Review, vol. 42, n. 2, 2008, p. 476-504.

HOWARD, Marc Morjé. Variation in Dual Citizenship Policies - in the Countries of the EU. International Migration Review, vol. 39, n. 3, 2005, p. 697-720. Disponível em http://www18.georgetown.edu/data/people/mmh/publication-7319.pdf. Acesso em $10 / 03 / 2016$.

KING, Gary; EPSTEIN, Lee. The Rules of Inference. The University of Chicago Law Review, vol. 69, 2002, p. 1-133. Disponível em http://gking.harvard.edu/files/rules.pdf. Acesso em 10/03/2016.

KING, Gary; KEOHANE, Robert; VERBA, Sidney. Designing Social Inquiry: scientific inference in qualitative research. Princeton: Princeton University Press. 1994

MASSEY, Douglas S.; ARANGO, Joaquín; HUGO, Graeme; KOUAOUCI, Ali; PELLEGRINO, Adela; TAYLOR, J. Edward. Theories of International Migration: a Review and Appraisal. Population and Development Review, vol. 19, n.3, 1993, p. 431-466. Disponível em http://media.library.ku.edu.tr/reserve/resfall12_13/intl551_AIcduygu/ week2.PDF. Acesso em 14/03/2016.

MINISTÉRIO PÚBLICO DO TRABALHO. MPT-PR recebe e autua denúncias de xenofobia contra haitianos, 2014. Publicado em [http://www.prt9.mpt.gov.br/procuradorias/45noticias/noticias-prt-curitiba/601-mpt-pr-recebe-e-autua-denuncias-de-xenofobiacontra-haitianos]. Disponibilidade 16/03/2016.

MONTIJANO, Elena Sánchez. La Politización de la Inmigración en España. In BARRERO, Ricard; GONZÁLEZ, Elisabet; MONTIJANO, Elena Sánchez (ed.). El Discurso Político en torno a la Inmigración en España y en la UE. Madrid: Gráficas Varona, 2008, p. 81-113. Disponível em http://extranjeros.empleo.gob.es/es/ ObservatorioPermanenteInmigracion/Publicaciones/fichas/archivos/El_discurso_ polxtico_en_torno_a_la_inmigracixn_en_Espaxa_y_en_la_UE.pdf.pdf. Acesso em $10 / 03 / 2016$.

PATARRA, Neide. Migrações internacionais de e para o Brasil contemporâneo: volumes, fluxos, significados e políticas. São Paulo em Perspectiva, v. 19, n. 3, 2005, p. 23-33. Disponível em http://www.scielo.br/scielo.php?script = sci_arttext\&pid = S010288392005000300002. Acesso em 09/03/2016.

PATARRA, Neide. Governabilidade das migrações internacionais e direitos humanos: o Brasil como país de emigração. In: I Conferência “Brasileiros no Mundo”. Brasília: Fundação Alexandre de Gusmão, 2008, p. 187-212. Disponível em https://sistemas. 
mre.gov.br/kitweb/datafiles/BRMundo/pt-br/file/Neide_Patarra.pdf. Acesso em 15/03/2016.

PATARRA, Neide. Políticas Públicas e Migração Internacional no Brasil. In CHIARELLO, Leonir (ed.). Las Políticas Públicas sobre Migraciones y La Sociedad Civil en América Latina. São Paulo: Scalabrini International Migration Network, 2011, p. 151-276.

PEDERSEN, Peder J.; PYTLIKOVA, Mariola; SMITH, Nina. Selection and Network Effects: Migration Flows into OECD Countries 1990-2000. European Economic Review, vol. 52, 2008, p. 1160-1186.

PIORE, Michael. Birds of Passage: Migrant Labor in Industrial Societies. Cambridge: Cambridge University Press, 1979.

REINO UNIDO. Acquisition by registration: certain persons born between 1961 and 1983. The British Nationality Act, 1981, Capítulo 61, Seção 4C. Disponível em http://www. legislation.gov.uk/ukpga/1981/61. Disponibilidade 16/03/2016.

REIS, Rossana. A Política do Brasil para as Migrações Internacionais. Contexto Internacional, vol. 33, 2011, p. 47-69. Disponível em http://www.scielo.br/scielo.php?script = sci_ar ttext\&pid $=$ S0102-85292011000100003. Acesso em 10/03/2016.

SASSEN, Saskia. Expulsions - Brutality and Complexity in the Global Economy. Cambridge: Belknap Press 2014.

SOARES, Guido Fernando Silva. Os Direitos Humanos e a Proteção do Estrangeiro. Revista de Informação Legislativa, vol. 41, 2004, p. 169- 204. Disponível em http://www2. senado.leg.br/bdsf/item/id/954. Acesso em 10/03/2016.

TODARO, Michael. A model of labor migration and urban unemployment in less-developed countries. The American Economic Review, vol. 59, 1969, p. 138-148.

UNITED NATIONS. International Migration Report 2013. Department of Economic and Social Affairs, Population Division, 2013. Disponível em http://www.un.org/en/ development/desa/population/publications/pdf/migration/migrationreport2013/ Full_Document_final.pdf. Acesso em 10/03/2016.

WALLERSTEIN, Immanuel. The Global Picture, 1945-90. In: HOPKINS, T. e WALLERSTEIN, I. (orgs). The Age of Transition - Trajectory of the World-System, 1945-2025. London: Zed Books. 1996.

WALLERSTEIN, Immanuel. World-Systems Analysis - An Introduction. Durham: Duke University Press. 2006. 